\title{
Optimizasyon Otomasyonu İçin Cplex Çözücüsünün Web Tabanlı Sunucu Üzerinden Çalıştırılması
}

\author{
Mustafa Zahid Gürbüz ${ }^{1}$, Onur Akçin² \\ 1 Başlıca Yazar, Doğuş Üniversitesi, Mühendislik Fakültesi, Bilgisayar Bölümü, İstanbul, Türkiye (ORCID: 0000-0002-5125-6378) \\ 2 Doğuş Üniversitesi, Fen Bilimleri Enstitüsü, Bilgisayar ve Enformansyon Bilimleri Bölümü, İstanbul, Türkiye (ORCID: 0000-0002-3213-4113)
}

(İlk Geliş Tarihi 13 Şubat 2020 ve Kabul Tarihi 31 Mart 2020)

(DOI: 10.31590/ejosat.688119)

ATIF/REFERENCE: Gürbüz, M. Z. \& Akçin, O. (2020). Optimizasyon Otomasyonu İçin Cplex Çözücüsünün Web Tabanlı Sunucu Üzerinden Çalıştırılması. Avrupa Bilim ve Teknoloji Dergisi, (18), 943-951.

\section{$\ddot{O} \mathbf{z}$}

Web uygulamaları günümüzde popüler olduğundan, erişim kolaylığı sebebiyle genellikle masaüstü uygulamaların yerine tercih edilmektedir. IBM ILOG CPLEX programı, matematiksel model çözme konusunda yöneylem araştırmalarında sıklıkla kullanılan bir programdır. Bu programın web ortamından sunulması, karar vericiye hem esneklik hemde kolaylık sağlamaktadır. Bu çalısmada, web arayüzünden girilen parametreler ile IBM ILOG CPLEX' e bağlanıp sonuçlar gösterilmiştir. Uygulama olarak optimizasyon problemlerinde bilinen reklam örneği kullanılmıştır. Günümüzde reklamcılık konusunda internet ve televizyon reklamcılı̆̆ı ön plana çıkmaktadır. Bunların hedef kitleye ulaşma konusunda iyi bir bütçe ayrılan reklamın önemi büyüktür. Uygulamada, forma üreten bir şirketin televizyonlara spot reklamlar vermesi ele alınmıştır. Şirketin hangi sektörde, belirli yaş aralıklarında kaç insana hitap ettiği ve reklam maliyetleri girilerek, hedef kitleye ulaşmasında en az maliyetle çıkması ve buna bağlı olarak reklam sayıları hesaplanması amaçlanmıştır. Uygulama masaüstü ve web uygulamalarından oluşmaktadır. Bu uygulamalar Microsoft tarafindan geliştirilen Visual Studio 2017 'de C\# programlama dili kullanarak yapılmıştır. Veritabanı olarak SQL Server 2012 kullanılmıştır. Masaüstü uygulamasının görevi, görev zamanlayıcı ile her dakika çalışıp, web uygulamasından gelen reklam parametlerini SQL Server tablolarından okumaktır. CPLEX bağlantı kodlarının karmaşık yapısı ve web uyumlu olmamasından dolayı bağlantı kodları masaüstü programda yazılmıştır. Web uygulaması ise aynı şekilde visual studio geliştirme aracı olan ASP.NET MVC 4 ile yazılmıştır. Burada reklam maliyetleri, hitap edilen yaş aralıklarındaki insan sayısı ve hedef kitlede ulaşmak istenen insan sayıları girilir. Görev zamanlayıcının cevabı dönmesi beklendikten sonra ekranda raporlar gösterilir. Sonuç olarak hedeflenen maliyet ve reklam sayıları başarılı bir şekilde elde edilerek, hangi reklama ne kadar bütçe ayrıbabileceği hesaplanmıştır. Belirlenen işlem sırasına göre ortaya çıkan sonuçlar, ekranda yüklenme süreleri gösterilerek kuyruğa alınması sağlanmıştır. Elde edilen sonuçlar ile girilen maliyetler, hesaplanan toplam reklam masrafları, hedeflenen yaş aralıklarının incelenmesini sağlayan istatistikler raporlarda gösterilmiştir.

\section{Running Cplex Solver on Web-Based Server for Optimization Automation}

\begin{abstract}
Because of web applications are popular nowadays, they are generally preferred over desktop applications because of their ease of access. And however This IBM ILOG CPLEX program is frequently used in operations research in mathematical model solving. It presents this program on the web and it provides flexibility and convenience to the decision maker. In this study, the parameters entered from the web interface which are connected to IBM ILOG CPLEX and the results are listed as an application, a specific advertising example is used in optimization problems. Today, internet and television advertising are so much famous. The importance of advertising, which is allocated a good budget in reaching their target audience is of great goal. In this application, company producing form to give spot ads to televisions. It is aimed to calculate the number of advertisements and to calculate the number of advertisements by reaching the target audience by entering the advertising costs and the number of people in which sector, in exact age ranges. The application consists of desktop and web applications. These applications were created by using c programming language in Visual Studio which was developed by Microsoft in 2017 and the SQL Server was used as the database in 2012. The goal of the desktop application is to run every minute with the task scheduler and read the advertising parameters from the web application
\end{abstract}


on the SQL Server tables. Because of the complex things of CPLEX connection codes and non web compatibility, those connection codes are developed in desktop software by hard. And however web application is developed in ASP.NET MVC 4 which is a visual studio development tool. Here, advertising costs, the number of people in the age range to be entered and the number of people desired to reach the target audience are entered. Since waiting for the task timer to return, reports keep being on the screen. As a result, the targeted cost and number of ads were obtained successfully and the budget for which advertisement was allocated was calculated. The results obtained according to the specified sequence of operations are displayed in the queue by showing the loading times on the screen. the results obtained, the costs entered, the total advertising costs calculated, statistics that allow the examination of targeted age ranges are shown in the reports.

Keywords: MVC 4, CPLEX Optimization, Software a Service.

\section{Giriş}

Tarihin her döneminde bilginin gücünün her alana hâkim olması, bilgiye daha kolay ve çabuk ulaşma isteğini de beraberinde getirmiştir. Bilgi paylaşımı ve iletişim kurma ihtiyacı, teknolojinin gelişimini sağlayarak interneti ortaya çıkarmıştır. Bugün geldiğimiz aşamada ise internet sadece bir iletişim aracı olmaktan çıkmış, sosyal, kültürel ve ekonomik hayatımızın bir parçası haline gelmiştir. (Dikener, 2011).

Teknoloji ilerledikçe ve bilgisayar kullanımı arttıkça, internet kullanımı daha popüler hale gelmiş, dünyanın neresinde olursa olsun bilgiye daha çabuk ve kolay ulaşma ve araştırma yapma imkânı da mümkün hale gelmiştir. Günümüzde mesaj gönderme ve alma, video konferansı, internet üzerinden telefonla görüşme, tv seyretme, gazete ve kitap okumak, alışveriş yapmak, eğitim, sağlık, seyahat faaliyetleri ile ilgili araştırma yapmak gibi hemen hemen her alanda hayatımıza girerek vazgeçilmez bir parçamız haline gelmiştir. (Öztürk ve Ayman, 2014).

İnternetin hayatımıza getirdiği olanaklar tüm alanlarda olduğu gibi reklamcılık alanında da önemli değişikliklere sebep olmuştur. İnternetin, doğrudan tepki alınabilen, geri dönüşleri birebir ölçülebilme imkânı getiren, kampanyaların performansını artırma, yatırımın getirisini en üst düzeye çıkarmak ve etkin bir marka aracı olduğu yadsınamaz bir gerçektir. Ayrıca diğer reklam alanlarına oranla daha etkin bir şekilde reklamlarımızı kişiselleştirmemize ve doğru hedef kitleye ulaştırmamıza imkân verir. (Dikener, 2011).

Yöneylem araştırması, işletmelerin yönetimlerinde karşılaşılan problemlere bilimsel yöntem, teknik ve araçların uygulanmasıyla en iyi çözümün bulunmasını sağlayan matematiksel karar verme yöntemidir (Yücel, 2004). Yöneylem araştırması teknikleri endüstri alanında ilk olarak 1947 yılında uygulanmaya başlanmıştır. Doğrusal problemleri çözmek için kullanılan Simplex Algoritması 1940’ lı yılların sonunda George Dantzig tarafından geliştirilerek işletmede uygulamaya koymuş ve bu alanda bir ilki başarmıştır (Metin ve Türkoğlu, 2018). Yöneylem araştırmasının yaygın tekniklerinden biri olan doğrusal programlama, bir problemi minimize veya maksimize etmek olarak tanımlanabilir. Buradaki hedef, belli bir amaca uygun olarak en karlı üretimi bulmaktadır (Yalgın, 1994).

Optimizasyon problem hayatın birçok alanında kullanılabilmektedir. Literatürde de yer alan diyet problemi, optimizasyon için uygun bir problemdir. Bu problemde kişi sağlıklı yaşam için belirli miktarda kaloriyi elde edebilecek besinleri alırken kadın ve erkekte farklılık gösteren basal metabolisma, egzersizte harcanan kalori gibi değerler hesaba katılarak en uygun besinin seçilmesi bir optimizasyon problemidir. (Saylı ve Akbulut, 2017).

Bazı optimizasyon problemleri karmaşıklığı nedeniyle matematiksekl modelleme olarak uygun zamanda çözülememktedir. Otomotiv yedek parça için raf optimizasyonu da bunlardan bir tanesidir. Bu probleme göre; çok çeşitli olan otomotiv yedek parçaları, belirli bir hacim kaplamaktadır ve piyasadaki sirkülasyonuna göre elde tutulan adedi değişmektedir. Hal böyle olunca fabrikadaki raf kapasitesi en kısıtlı kaynaklardan bir tanesi haline gelmektedir. Bu nedenle yedek parçaların raflara çok verimli bir şekilde yerleştirilmesi gerekmektedir. (Özçelik ve Gündüz, 2019)

$\mathrm{Bu}$ çalışmada sistemin test edilmesi amacıyla çok bilinen optimizasyon problemlerinden biri olan olan reklam örneği ele alınmıştır. Reklamlarda hitap edilen insan sayısı ve maliyet önemli bir yere sahiptir. Özellikle televizyonlara verilen reklamlarda maliyet yükseliği ve hedef kitle seçimleri dikkat çekmektedir. (Mucuk, 2010) Uygulamadaki amaç, web arayüzünden girilen basketbol ve voleybol maçlarının maliyetleri, bunların ulaştığı toplam yaş aralıkları ve hedef kitlede ulaşılması istenen yaş aralıklarının girilerek, toplam reklam masraflarını incelemektir. Bu sayede görmek istediği hedef kitlede minimum maliyeti ve hangi spor müsabakasına kaç adet reklam kullanılcağı hesaplanmaktadır. Elde edilen sonuçlar istatistik şeklinde sunulmuştur.

IBM ILOG CPLEX, matematiksel model konusunda literatürde sık kullanılmaktadır. Varlı, Ergişi ve Eren (2017), çalışmalarında hemşirelerin çalışma günlerini mümkün olduğu kadar dengeli dağıtmış ve buna uygun olarak CPLEX optimizasyonu ile hedef programlama modeli geliştirmiştir. Senol ve Güngör (2011), menü planlamalarının çözüm önerisinde, yöneylem tekniklerinden biri olan 0-1 tamsayılı programlama modeli uygularak CPLEX optimizasyonu ile menü planlamasını yapmıştır. Doğruyol vd. (2019), boyahane bölümünde oluşan verimsiz çizelgemeyi önlemek ve ürünleri uygun zamanda montaj hattına ulaştırıp gecikmeleri azaltmak amacıyla, karar destek sistemi oluşturmuştur. Modelleme CPLEX ile oluşturulmuş, önerilen sezgisel yöntemler Excel Visual Basic for Applications (VBA) programı ile kodlanmıştır.

CPLEX' te opl dili kullanılarak model geliştirilir. Bu model mod uzantılı bir dosyaya kaydedilir. Ayrıca veriler için mod dosyası kullanılabileceği gibi ayrı bir dat dosyası oluşturalarak model çalıştırılabilir.

Çalışma dört bölümden oluşmaktadır. İlk bölümde web uygulamaları ile ilgili bilgiler, ikinci bölümde kullanılan metodlar ve yöntemler, üçüncü bölümde çalışmada elde edilen araştıma sonuçlarının değerlendirmesi, son bölümde ise elde edilen sonuçlardan bahsedilmiştir. 


\section{Materyal ve Metot}

\subsection{Görev Zamanlayıcı}

Görev zamanlayıcı, seçilen günlük, haftalık, aylık gibi zamanlarda seçilen saat veya dakika aralıklarına göre otomatik çalışan bir windows programıdır. Görev zamanlayıcı sayesinde, çalışması istenilen bir program, belirlenen zamanlarda otomatik olarak kendiliğinden çalıştırılabilir. Uygulamanın otomatik çalışması için ilk olarak görev oluşturup, zaman ve saat aralıklarını seçip, uygulamayı tanitmak gerekmektedir.

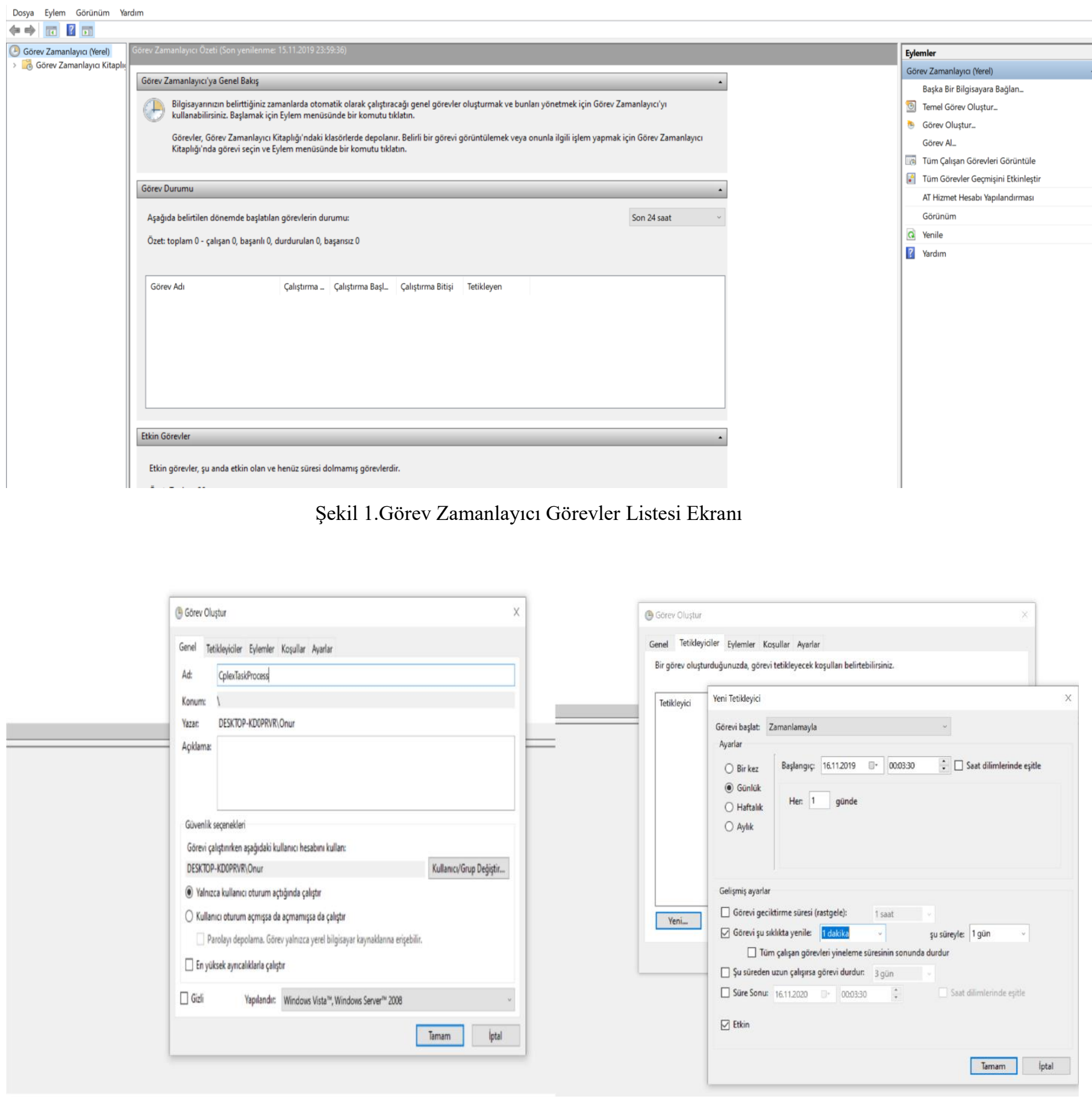

Şekil 2. Görev Tanımlayıcı Tanımlama Ekranı

Görev zamanlayıcıyı kurmak için ilk olarak windows ekranından Şekil 1'deki görev listesi ekranı açılır. Daha sonra görev oluştura tıklayıp Şekil 2'deki ekran karşımıza çıkmaktadır. Buradan görevin adı ve projenin çalışma aralıkları girilir. 


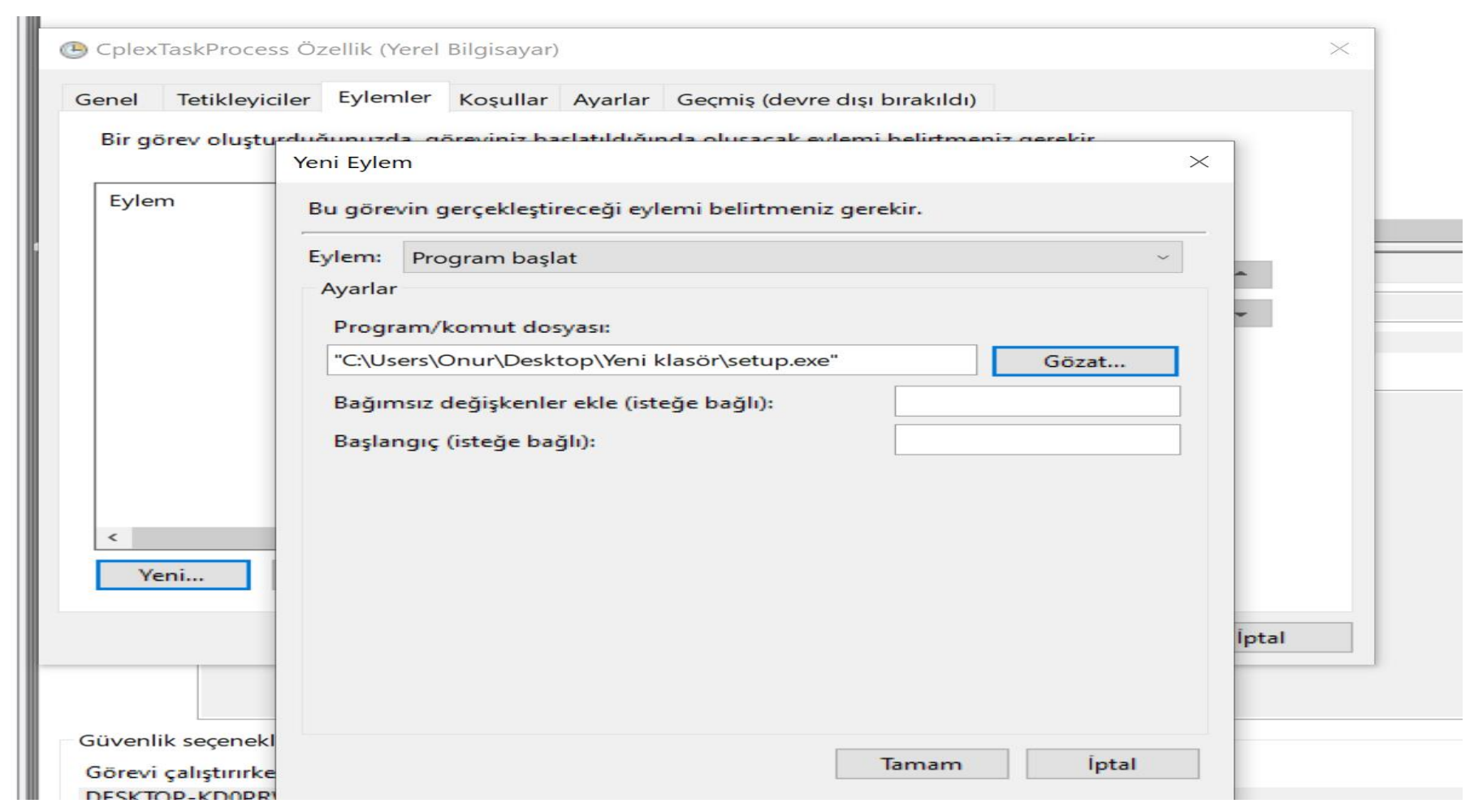

Şekil 3. Eylem oluşturma adımı

Çalışma zamanları belirlendikten sonra, yeni eylem oluşturulur. Burada otomatik çalışacak programın komut dosyası belirlenir. Burada, çalışmada kullanılacak olan konsol uygulamasının çalıştırılabilir dosya yolu gösterilmiş̧tir. Bu adımda şeçildikten sonra görev zamanlayıcıda oluşturulan program, her dakika web arayüzünden gelen CPLEX görevlerini kontrol edecektir.

\subsection{Kodlama Ortamı}

Microsoft, .NET platformunu geliştirirken platform ve programlama dili bağımsız, güvenli, tamamen nesne tabanlı bir sistem kurmayı hedeflemiş ve bunu da başarmışıtır. Microsoft'un 10 yıllık vizyonu olan bu teknoloji dünyasında ve Türkiye'de giderek artan sayıda yazılım geliştirici tarafından kullanılmaktadır. .NET, framework denilen bir çekirdek sistem üzerinde çalışmaktadır. Framework içerisinde bulunan yapılar sayesinde de geliştirilen uygulamalar hızlı, güvenilir, .NET platformunu destekleyen diğer programlama dilleride ile etkileşimli uygulamalar halini alır. .NET Framework ise, yazılım geliştirme ve projenin çalışabilmesi için gerekli çekirdek sistemdir. .NET teknolojilerinin çalışabilmesi için uygulamanın çalışacağı sistemde mutlaka .NET Framework yüklü olmalıdır. Amaçlanan, projelerin işletim sistemi ve donanımsal ortamlardan soyutlanarak geliştirilmesini sağlamaktır (Turan, 2018).

Bu çalışmada iki farklı proje birbiri ile bağlantılı olarak çalışmaktadır. Birinci proje, konsol uygulamasıdır. Bu uygulama, Visual Studio geliştirme aracı kullanılarak, oluşturulmuştur. Konsol uygulamaları masaüstü uygulamalardır. Girdiler veya sonuçlar konsol ekranında gerçekleşir. Çalışmadaki konsol uygulamasındaki amaç, yüklenen mod uzantılı dosya ve girilen parametreleri dat uzantılı dosya üzerine yazdırı CPLEX' e bağlayarak, sonuçları görev zamanlayıcı ile getirmektir. Kodlamada C\# dili ile ADO.NET kullanılmıştır. ADO.NET veri erişimi, .NET Framework programcıları için kullanılan sınıflar kümesidir. ADO.NET, dağıtılmış, veri paylaşımı uygulamaları oluşturmak için zengin bir bileşen kümesi sağlar. İlişkisel erişimi, XML ve uygulama verileri sağlayan, .NET Framework ayrılmaz bir parçasıdır (Balcı, 2018:9).

Bu çalışmadaki ikinci proje web uygulaması oluşturmaktadır. Uygulama aynı şekilde Visual Studio geliştirme aracı kullanılarak, ASP.NET MVC 4 ile yapılmıştır. MVC 'nin ortaya çıkması günümüzden yaklaşık 40 yıl öncesine dayanmaktadır. Model - View Controller kelimelerinin baş harflerinden MVC, Asp.net teknolojisi üzerine geliştirilmiş teknolojidir. Bu mimariyi ilk olarak 1979 yılında Trygve Reenskaug oluşturmuştur. İlerleyen yıllarda bu mimariyi Microsoft, Visual Studio ortamına dahil etmiştir (Hacıoğlu ve Güneş, 2019:91). Model-View-Controller sınıflarının kendilerine özel ayrı görevleri vardır. Model, veritabanındaki verileri temsil eder. View ve controller arasındaki veri iletişimini sağlar. View, kullanıcıların gördüğü html sayfadır. Controller, uygulamaya gelen talepleri yönetir. Burada action metodları bulunur. Bu metodlar, gelen talepleri uygun View ve Model üzerinden değerlendirmeye alır. Kodları, model, view ve controllere bölerek karışıklğı önler ve düzen sağlar. Browser uyumluluğu ve SEO optimizasyonu bir diğer avatajlarındandır.

Uygulama arayüzünde, mobil uyumlu her ekrana uygun bir tasarım olmasını sağlayan CSS framework 'ü bootstrap teknolojisi kullanılmıştır (trbootstrap, t.y.). SQL kaydı ve tablolardan liste çekme işlemlerde, esneklik ve hız katması bakımından Entitiy Framework kullanılmıştır. Entity Framework, Microsoft'un, .NET nesneleri kullanarak veri tabanıyla çalışmasına imkan tanıyan bir nesne ilişkisel eşleyicisidir. Bu yapı ile kodlamada, veri tabanına erişim ve değişiklik için yazılması gereken fazla kod önlenir (Balcı, 2018:7). 
CPLEX’ten dönen cevaplar bazen geç sürebilmektedir. Bu sebeple, gelen sonuç listelerinin HTML sayfasında görünümlerinde sunucu yükünü azaltması bakımından ve Cplex süresinden doğan süre zaafını azaltması bakımından JavaScript ve Ajax kullanılmıştır. AJAX metotları yardımıyla sayfa üzerinde oluşan çeşitli olaylarda (buton tıklama, üzerine gelme vs.) sunucu ile veri alışverişinde bulunulur ve gelen verilere göre sayfa üzerinde çeşitli değişiklikler yapılır (Şen, 2008:120).

\subsection{Optimizasyon Otomasyonu}

$\mathrm{Bu}$ çalışmanın ikinci projesi olan web programında reklam optimizasyonu için parametre girişler ekranları tasarlanmıştır. Şekil4 ‘teki gibi şeçilen mod uzantılı dosyanın yüklenmesi gereklidir. Bu dosya görev zamanlayıcı ile çalışacak konsol uygulaması için CPLEX ile bağlantı kurmayı sağlar. Çalışmada optimizasyon görev girişleri web uygulaması üzerinden yapılmaktadır. Uygulamanın görüntüleri aşă̆ıdaki gibidir.

\section{CPLEX CONNECT}

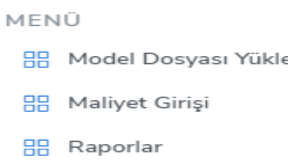

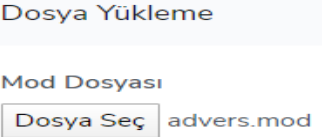

YÜKLE

Şekil 4. Dosya yükleme

\section{CPLEX CONNECT}

MENÜ
㗊 Model Dosyası Yükle
㗊 Maliyet Giriși
哭 Raporlar

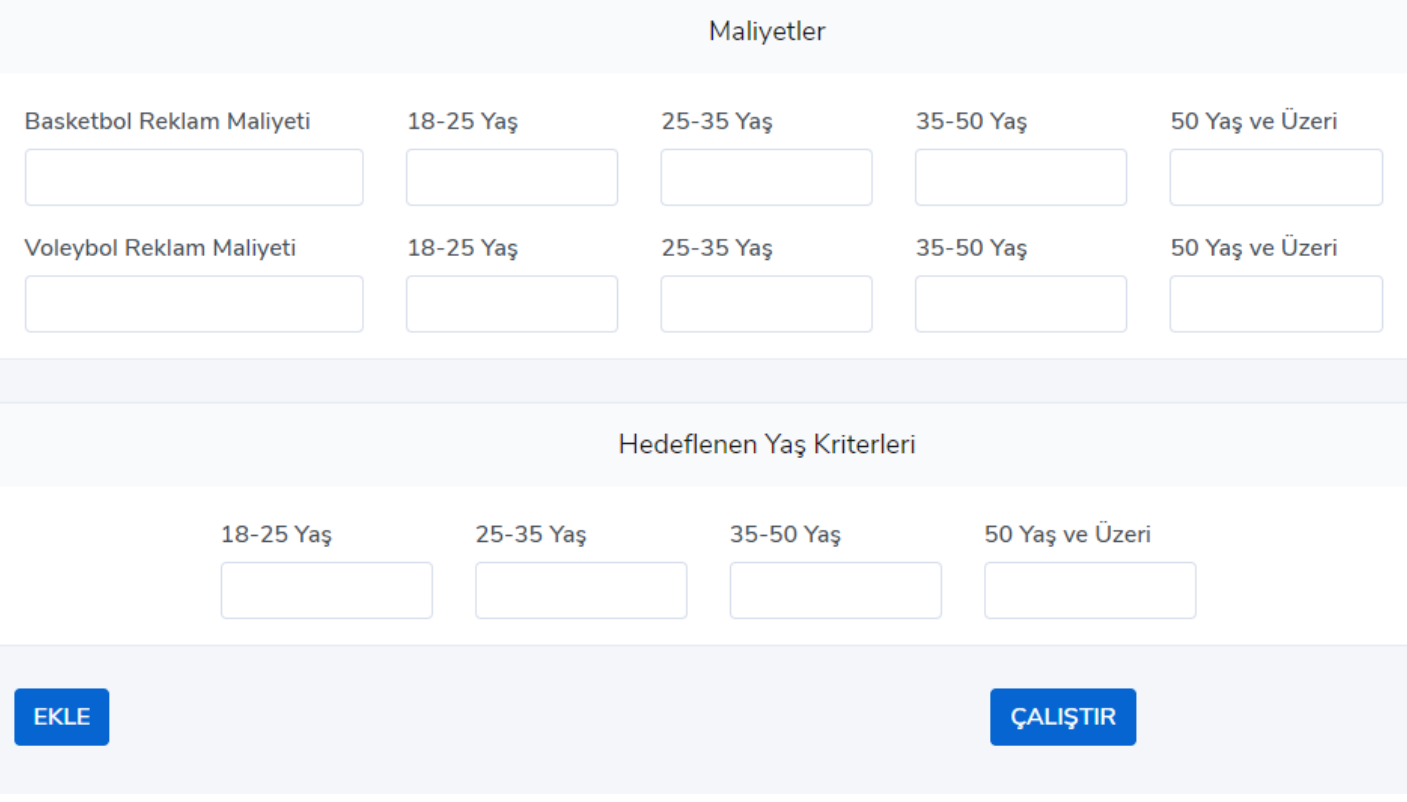

Şekil 5. Arayüz anasayfası 

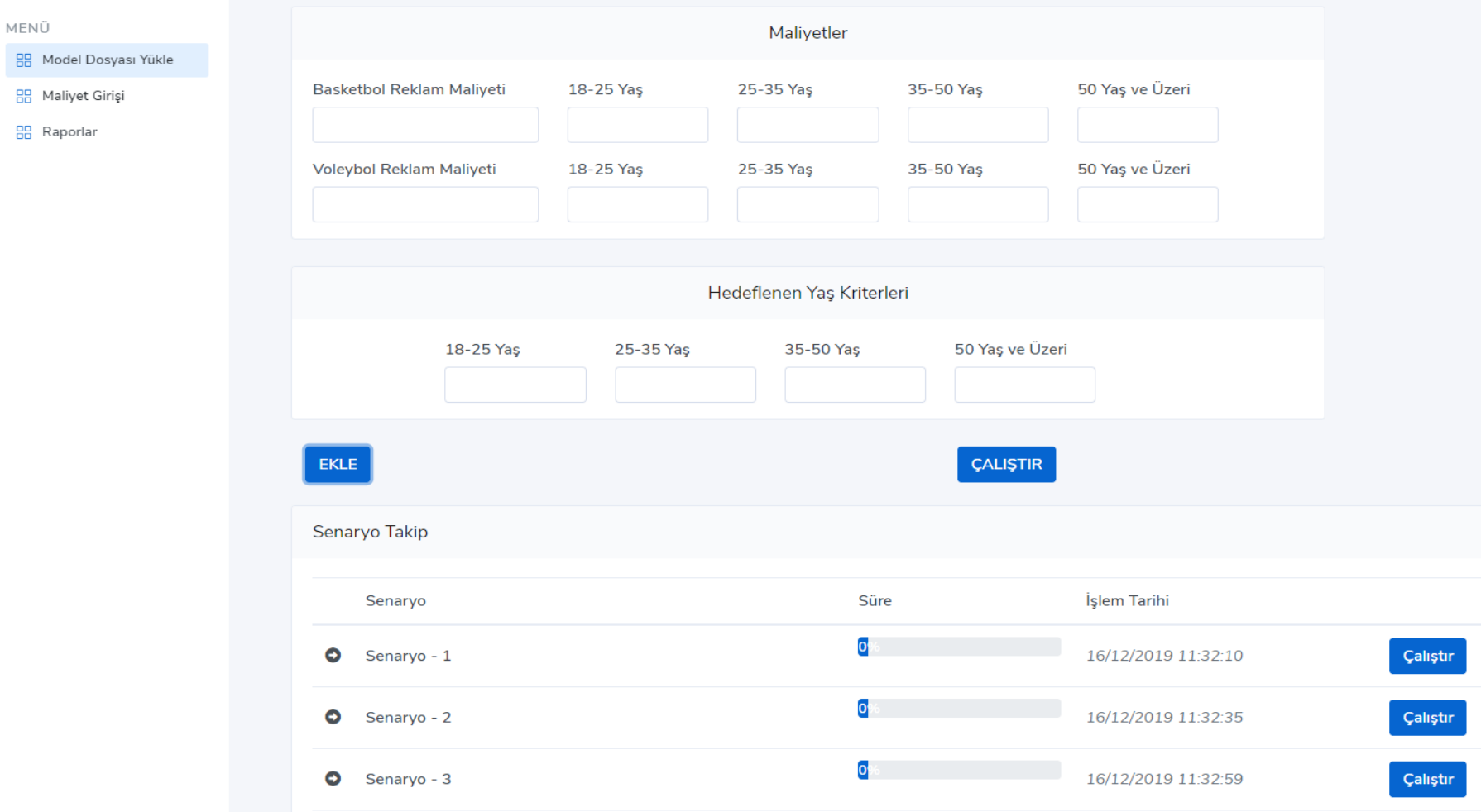

Şekil 6. Girişler

Şekil 5'de arayüzün parametre girişleri verilmiştir. Buradan istenen girişler yapılıp ekle butonuna basılarak, CPLEX te çalışacak olan Şekil 6'deki listeler listelenir. Buradaki ÇALIŞTIR butonu, listelenen verilerin, CPLEX ' ten dönen cevaplarını alır. Listedeki satırda bulunan Çalıştır butonu ise, sadece o satıra ait olan CPLEX cevabının sonucunu vermektedir. Html sayfasında gözüken listeler için ajax metodu kullanılmıştır.

Senaryolar çalıştırıldığında, konsol uygulaması yeni görevleri kontrol etmeye başlar. CPLEX ' in çalışması için mod ve dat uzantılı dosyalar gereklidir. Web tarafindan yüklenen mod uzantılı dosya ve girilen parametreler dat dosyasına yazdırılarak, bu iki dosyanın CPLEX' e bağlanması sağlanır. Bağlanıp sonuçlar döndükten sonra cevapların SQL 'e kaydı yapılır. Buradan dönen süreler progressbarlar ile gösterilmiştir. Progressbarda işlem sonuçları \%100 olduğunda kullanıcıya, senaryoların yanına bulunan icona basıldığında popup ile gösterilmektedir. Console uygulamasından dönen CPLEX cevapları için çekilen listede, C\# tarafinda Entitiy Framework kullanılmıştır.

\section{Araştırma Sonuçları ve Tartışma}

Çalışmada çeşitli senaryo girişleri yapılmıştır. Girilen parametreler aşağıdaki tablolarda verilmiş̧ir. 
European Journal of Science and Technology

Maliyetler

Basketbol Reklam Maliyeti

20.000

18-25 25-35 35-50 50+

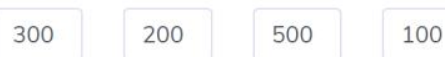

Voleybol Reklam Maliyeti

40.000

\begin{tabular}{|c|c|c|}
\hline $8-25$ & $25-35$ & $35-50$ \\
\hline 600 & 400 & 100 \\
\hline
\end{tabular}

Hedeflenen Yaş Kriterleri

\begin{tabular}{|c|c|}
\hline $18-25$ & $25-35$ \\
\hline 15000 & 30000 \\
\hline $35-50$ & $50+$ \\
\hline 25000 & 40000 \\
\hline
\end{tabular}

Maliyetler

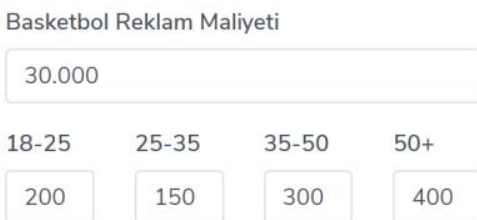

Voleybol Reklam Maliyeti

50.000

\begin{tabular}{|c|c|c|c|}
\hline $18-25$ & $25-35$ & $35-50$ & $50+$ \\
\hline 200 & 500 & 600 & 500 \\
\hline
\end{tabular}

Hedeflenen Yaş Kriterleri

\begin{tabular}{|c|c|}
\hline $18-25$ & $25-35$ \\
\hline 15000 & 20000 \\
\hline $35-50$ & $50+$ \\
\hline 25000 & 27000 \\
\hline
\end{tabular}

Maliyetler

Basketbol Reklam Maliyeti

10.000

$\begin{array}{llll}18-25 & 25-35 & 35-50 & 50+\end{array}$

\begin{tabular}{|l|l|l|l|}
\hline 200 & 100 & 300 & 400 \\
\hline
\end{tabular}

Voleybol Reklam Maliyeti

30.000

18-25 25-35 35-50 50+

\begin{tabular}{|l|l|l|l|}
\hline 200 & 700 & 200 & 500 \\
\hline
\end{tabular}

Hedeflenen Yaş Kriterleri

18-25 25-35

\begin{tabular}{l|l}
10000 & 15000
\end{tabular}

$35-50 \quad 50+$

$18000 \quad 17000$

Şekil 7. Senaryo A-B-C Ekranı

Senaryo Takip

\begin{tabular}{|c|c|c|c|}
\hline$\theta$ & Senaryo - 1 & 100 & $16 / 12 / 201911: 33: 59$ \\
\hline$\theta$ & Senaryo - 2 & 100 & $16 / 12 / 201911: 33: 59$ \\
\hline$\theta$ & Senaryo - 3 & 100 & 16/12/2019 11:33:59 \\
\hline
\end{tabular}

Şekil 8. Biten Senaryolar

Çalışma tamamlandığında, Şekil 8'deki gibi \%100 yüklenme sağlanmış, cevaplar görünüme hazır hale gelmiştir. Solda görünen iconlara tıklandığında, çıkan popuplar aşağıda Şekil 9' da verilmiştir. 
Şekil 10 ‘da, hesaplanan senaryolar için istatistik dilimleri hazırlanmıştır.
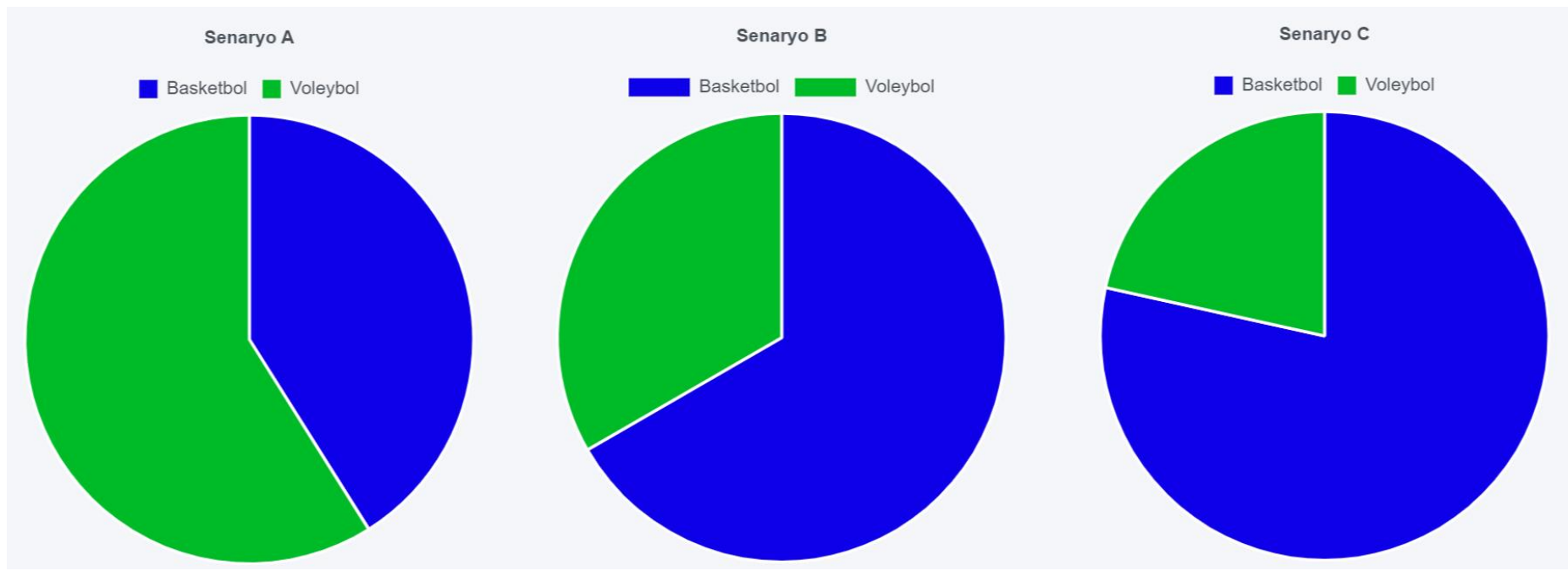

Şekil 10. İstatistikler

Litaretürdeki çalışmalarda genellikle masaüstü veya excel tabanlı uygulamalardır. Bu yazılım sayesinde problem, web ortamına sokulmuştur. Uygulama, mod uzantılı model dosyası ve parametre değişikliği yapıldığında gerekli esnekliklere sahip olacak şekilde kodlanmıştır.

\section{Sonuç}

Sonuç olarak Cplex programını web ortamından çalıştırmak için bir metod geliştirilmiştir. Bu yönteme göre son kullanıcı model parametrelerini web ortamından girerek yine web üzerinden tetiklenen bir yöntemle optimizasyon sunucusunu çalıştırabilmektedir. Bu sistemin başarısını göstermek için reklam optimizasyonu örneği kullanılmıştır. Bu örnek ile çalışmanın başarılı olduğu görülmüştür.

CPLEX bağlantı kodları karmaşık ve web uyumlu olmadığından uygulama iki etapta gerçekleşmiş, console uygulaması görev zamanlayıcı ile çalışmış, gelen senaryo girişleri, SQL Server'daki tabloları okuyup, IBM ILOG CPLEX yardımıyla cevapları dönmüştür. Cevaplar sunulurken, işlem önceliğine göre kuyruğa alınmış ve yüklenme süreleri başarıyla ekranda gösterilmiştir. Bu senaryoların sonuçları ve toplam maliyetleri, listelen satırlarda detaylı olarak tıklanan popuplarda sunulmuştur. Sunulan sonuçlara göre senaryo-A modeli için 39 adet basketbol, 56 adet voleybol ile elde edilen minimum maliyet 3000 TL, senaryo-B modeli için 50 adet basketbol, 25 adet voleybol ile elde edilen minumum maliyet 2750 TL, senaryo-C modeli için 51 adet basketbol, 14 adet voleybol ile elde edilen minimum maliyet 932 TL olarak hesaplanmıştır. Elde edilen sonuçlara göre istatistikler dilimler raporlar sekmesinde, chart yardımıla gösterilmiştir. 
Bu çalışma web socket yapıları kullanılarak daha da geliştirilebilir. Ayrıca değişik optimizasyonularının parametre girişlerini otomatikleştirmek için modele göre otomatik oluşturulan dinamik bir parametre giriş ekranı tasarlanabilir. Ek olarak verilen modele göre yapay zekâ kullanılarak otomatik senaryolar oluşturularak karar vericiye destek olabilir. Karar vericinin parametrelerdeki küçük değişikliklere göre bütün optimizasyonu değiştirmeyecek kadar toleransını belirttiği ve aynı zamanda da Cplex çözücüsü içerisinde de hizmet olarak sunulan duyarlılık analizi sonuçları da ek olarak sunulabilir ve senaryoların daha verimli bir şekilde incelenmesi sağlanabilir.

\section{Kaynakça}

Dikener, O. (2011). İnternet Reklamcılığında Web Sitesi Tasarımının Önemi. Erciyes İletişim Dergisi, 2(1), 152-166

Öztürk, M., \& Ayman, M. (2007). Web sayfalarının halkla ilişkiler amaçlı kullanımı. Selçuk Üniversitesi İletişim Fakültesi Akademik Dergisi, 4(4), 57-66.

Metin, S., \& Türkoğlu, İ. (2018) Doğrusal Programlama Yöntemleri Kullanılarak Küçük İşletmelerdeki Kar Paylarının Artırılması: Mert Cam Örneği. Munzur Üniversitesi Sosyal Bilimler Dergisi (MÜSBiD), 6(12), 106-117.

Yalgın, A. O. (1984). Doğrusal Programlama ve Madenciliğe İlişkin iki Basit Örnek. Bilimsel Madencilik Dergisi, 23(3), 25-40.

Hacıoğlu, T., \& Güneş, A. (2019) Çok Katmanlı Çok Kullanıcılı Web Sistemlerinde Performans Analizi ve Bir Uygulama. Engineering Sciences, 14(3), 88-103.

Yücel, M. Pazarlama Problemlerinin Çözümünde Yöneylem Araştırmasının Önemi. Fırat Üniversitesi Doğu Araştırmaları Dergisi, 2(2), 70-76.

Balcı, T. (2018). Entitiy Framework'ün Farklı Veritabanlarındaki Performans Analizi. Yüksek Lisans Tezi, Kırıkkale Üniversitesi, Kirıkale

Turan, F. (2018). Asp.Net Mvc 4 Teknolojilerini Kullanarak Bir E-Ticaret Sitesi Uygulamasının Geliştirilmesi. Yüksek Lisans Tezi, Beykent Üniversitesi, İstanbul

Şen, Ş. (2008). Web Part ve Ajax Teknolojileri İle Kişiselleştirilebilir Portal Uygulaması. Yüksek Lisans Tezi, Ege Üniversitesi, İzmir

Varlı, E., Ergişi, B., \& Eren, T. (2017). Özel Kısıtlı Hemşire Çizelgeleme Problemi: Hedef Programlama Yaklaşımı. Erciyes Üniversitesi İktisadi ve İdari Bilimler Fakültesi Dergisi, (49), 189-206.

Şenol, S., \& Güngör, İ. Menü Planlama Sorununa Karma Tamsayılı Programlama Modeli İle Çözüm Önerisi. Yüksek Lisans Tezi, Süleyman Demirel Üniversitesi, Isparta

Doğruyol, M. C., Duran, E., Görgülü, G., Gülhan, İ., Kuruç, A. P., Özsümbül, K., Uğuz, B. \& Anaç, C. Boya Atölyesinde İş Çizelgeleme Problemi. Sistem Tasarımı Proje Özetleri, 49.

Sayl, A., Akbulut, C., (2017), Analysis, Design and Implementation of Diet Control System, European Journal of Science and Technology Vol. 7, No. 11, pp. 2-6, December 2017

Mucuk, İ. (2010). Pazarlama ilkeleri. İstanbul: Türkmen Kitabevi

Özçelik, T.Ö., Gündüz, G., (2019) Sezgisel Algoritmaları Kullanarak Raf Optimizasyonu Çalışması ve Bir Yazılım Uygulaması, Avrupa Bilim ve Teknoloji Dergisi Sayı 16, S. 977-982, Ağustos 2019

Trbootstrap. (t.y.). Erişim adresi https://trbootstrap.com 